\title{
Track measurement by Kyushu Shinkansen cars in commercial service
}

\author{
H. Moritaka ${ }^{1} \&$ T. Matsumoto ${ }^{2}$ \\ ${ }^{I}$ Omuta Track Maintenance Depot, Kyushu Railway Company, Japan \\ ${ }^{2}$ Track Maintenance Division, Track \& Facilities Department, \\ Kyushu Railway Company, Japan
}

\begin{abstract}
The Kyushu Railway Company (JR [Japan Railway] Kyushu) has introduced, for the first time in Shinkansen trains in Japan, a device that can measure all track irregularity using cars in commercial service. With that, special measurement cars were no longer needed, and frequent monitoring of the status of tracks became possible.

The track irregularity measurement device employs an inertial measurement method, whereby track irregularity can be measured at a single cross-section. It is mounted with a special attachment base at the center of the bogie frame on rear bogies of the lead cars at both ends of the train. Measurement operations are done by remote control from PCs at the wayside.

Devices that can measure track irregularity, body vibration acceleration, and axle box vibration acceleration were mounted to Shinkansen cars in commercial service introduced in August 2009, and use of the devices commenced. Those cars have run 458,299 $\mathrm{km}$ as of the end of April 2010, and track measurement was made without problems in the 27,412 km for which measurements were taken.

Keywords: Kyushu Shinkansen, track measurement by Kyushu Shinkansen cars in commercial service, the inertial versine method.
\end{abstract}

\section{Introduction}

The Kyushu Railway Company (JR [Japan Railway] Kyushu) has been proceeding since FY 2005 with the technical development of measurement functions for track irregularity, vibration acceleration, and axle box vibration acceleration to add to Shinkansen cars in commercial service. As a result, the 
company has completed the mounting of track measurement devices to new Shinkansen rolling stock (U7 trainsets) introduced this fiscal year, and good track measurement has been achieved. This paper will give an overview of general track measurement by Kyushu Shinkansen cars in commercial service.

\section{Composition of the track measurement device for the Kyushu Shinkansen}

Figure 1 shows an image of the track measurement device mounted to a Shinkansen car in commercial service. The track measurement device covered here is composed of five major devices: track irregularity detector, vibration acceleration detector, axle box vibration acceleration detector, position detector, and control PC. The track measurement device is mounted on the lead cars (car Nos. 1 and 6).

Technical development of the individual devices was conducted while gaining the consensus of the Rolling Stock Division from the standpoints of high-accuracy measurement, no disruption to bogie running performance, and no reduction to passenger cabin space [1] In this section, we will cover the functions of the individual devices.

\subsection{Track irregularity detector}

The track irregularity detector-the core component of the general track measurement system created - utilizes the inertial versine method contrived by the Railway Technical Research Institute in which high-accuracy measurement of track can be expected without the need for large-scale modifications to rolling stock (bogies and body) [2]. The inertial versine method applies the inertial measurement method that utilizes the phenomenon whereby rolling stock vibrates due to track irregularity, and the results especially are output as versine irregularity and allow simultaneous measurement of gauge and cross level. In that way, the inertial versine method that can measure the five basic items of track irregularity on a single cross section allows the track irregularity detector to be mounted without a base of the body and multiple bogies as with previous measurement methods (versine method and asymmetrical chord offset method).

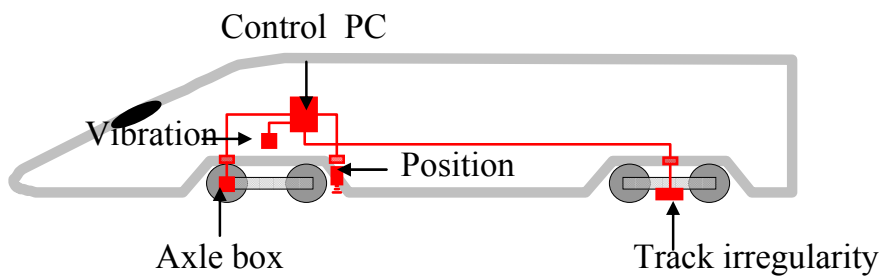

Figure 1: Image of mounting to Shinkansen rolling stock. 
It can thus be said to be a measurement method fitting all-motor-car Kyushu Shinkansen cars in commercial service.

Figure 2 shows the specific mounting method for the track irregularity detector. The structure has a special attachment base at the center of the bogie frame, and the detector is rigidly coupled to that. This detector has a double box construction with a steel outer box and sensors (displacement gauge, gyro, accelerometer) on a high-precision aluminum base protected from vibration in the inner box. Bogie strength and running stability were taken into consideration as much as possible in design. The track irregularity detector is mounted on the rear bogies of the lead cars taking into consideration axle load balance, avoidance of danger in impact with obstructions, and workability in the pit line at the depot.

\subsection{Vibration acceleration detector}

The vibration acceleration detector is mounted under the floor near the center of the lead bogie. It detects vertical and horizontal vibration acceleration of the body.

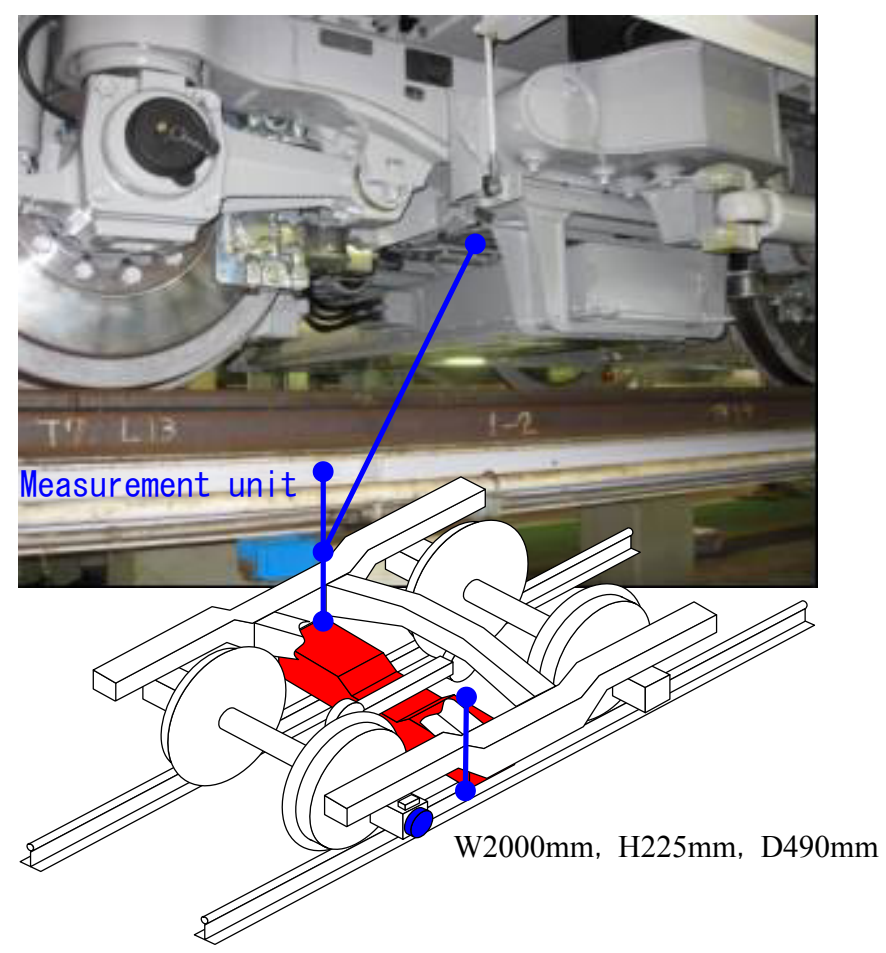

Figure 2: $\quad$ Measurement unit dimensions. 


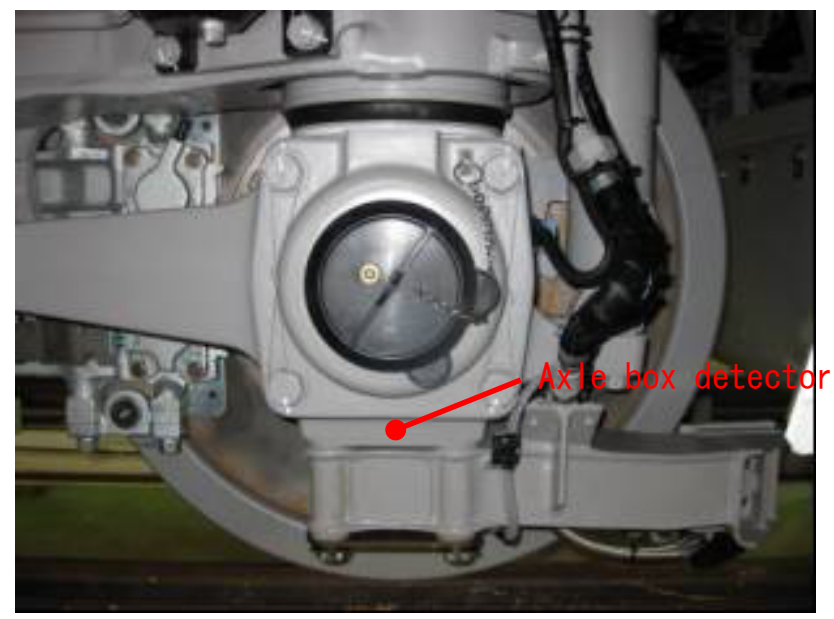

Figure 3: Axle box vibration acceleration detector.

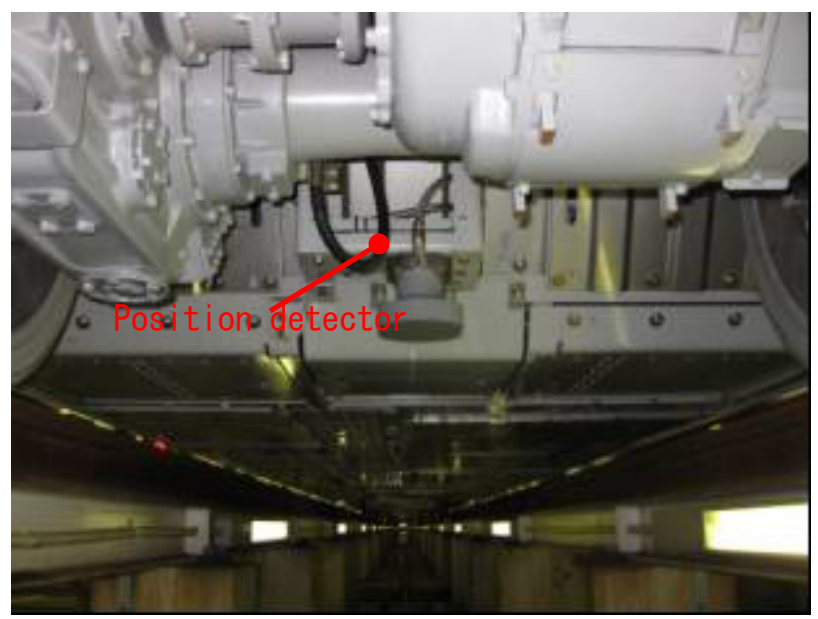

Figure 4: $\quad$ Position detector.

\subsection{Axle box vibration acceleration detector}

Axle box vibration acceleration detector is mounted to the bottom of the axle boxes of both wheels on the front axle of the lead bogie (Fig. 3). It detects vertical and horizontal vibration acceleration of the axle.

\subsection{Position detector}

The position detector is mounted under the body at the rear axle of the lead bogie. That device detects beacons installed every $500 \mathrm{~m}$ to detect location information. That information along with $0.25 \mathrm{~m}$ sampling pulses makes appropriate alignment of measurement data. 


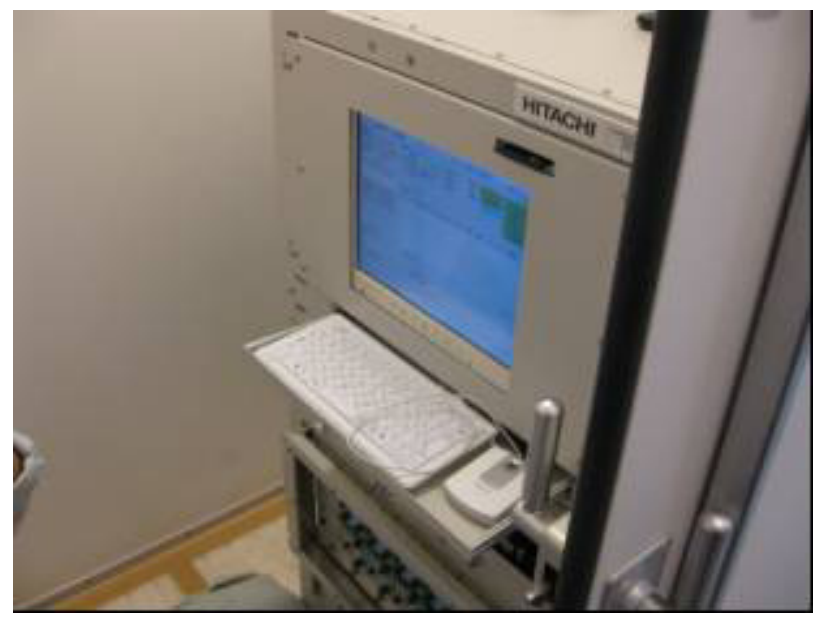

Figure 5: $\quad$ Control PC.

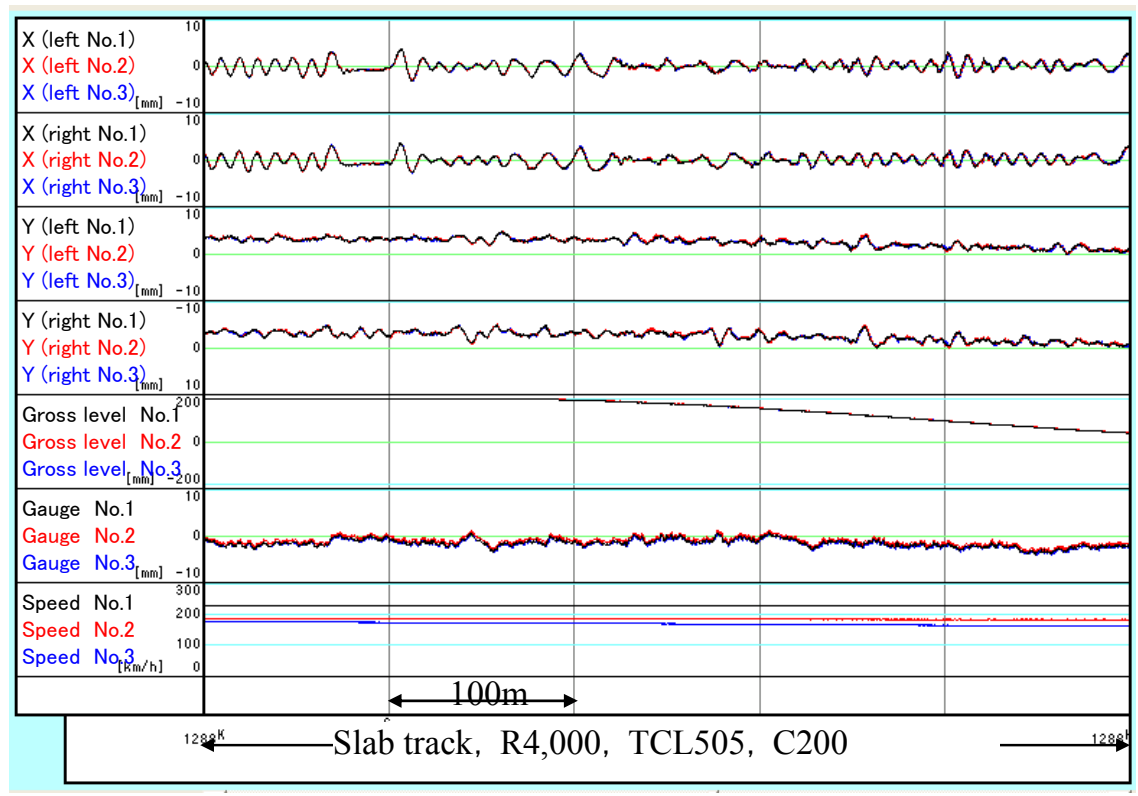

* X: 10m chord longitudinal level irregularity Y: $10 \mathrm{~m}$ chord alignment

Figure 6: Example of track measurement wave forms for Shinkansen cars in commercial service. 


\subsection{Control PC}

The control PC is mounted in the equipment room between the driver's cab and passenger cabin. That unit is made up components such as the measurement control part, acceleration control part, power control part, and data recorder. Compactness was pursued thoroughly so it could reside along with other rolling stock control devices, making effective use of empty space so it could be mounted in the equipment room without reducing passenger cabin space.

Furthermore, wayside notebook PCs are linked with the onboard control PC by a network to form a system where settings for initial conditions and measurement start/stop can be made by remote control. With that function, measurement personnel do not need to be on the train, and car scheduling for measurement is not needed. The system also compensates the weak point of inertial measurement-low-speed range measurement-by simultaneous measurement between cars Nos. $1 \& 6$.

\section{Wave form of track measurement by Shinkansen cars in commercial operation}

Figure 6 shows an example of the track irregularity wave form acquired in general track measurement by Kyushu Shinkansen U7 trainsets. The features for this section are as follows.

[Features, etc.]

- Directly fastened Type 8 frame-shaped slab

- Open section

- Near 4,000 m radius ETC

- $200 \mathrm{~mm}$ cant

- $12 \%$ downhill grade

The track measurement wave forms for three passes shown in Figure 6 were acquired from the track irregularity measurement device on car No. 1. The three wave forms match extremely well, and track conditions such as amount of versine in the curve and appropriate amount of cant are appropriately captured. We can thus see that the device has very high measurement accuracy.

\section{Conclusion}

Highly accurate monitoring of track conditions became possible by achieving general track measurement with Shinkansen cars in commercial service, and we can expect further improvement in safety. Initial costs and running costs can also be reduced, and we can expect large expenditure reduction effects. JR Kyushu plans to add the track measurement function to U9 trainsets to be introduced next fiscal year to build an even more complete monitoring system. 


\section{References}

[1] Moritaka, H., Matsumoto, T. \& Yazawa, E., Technical development for general track measurement by Kyushu Shinkansen Cars (Japanese). Journal of the Japan Railway Civil Engineering Association, pp. 921-923, 2009.

[2] Moritaka, H., Yazawa, E. \& Tsubokawa, Y., Performance evaluation of inertial versine track irregularity detector and investigation of detecting method in low speed range (Japanese). Proc. Of the $46^{\text {th }}$ Academic Lecture Meeting of Japan Society of Civil Engineers: Fukuoka, Japan, pp. 73-74, 2008. 